\title{
Protecting effect of PrP codons M142 and K222 in goats orally challenged with bovine spongiform encephalopathy prions
}

\author{
C. Fast ${ }^{1 \dagger}$, W. Goldmann ${ }^{2 \dagger}$, P. Berthon ${ }^{3 \dagger}$, K. Tauscher $^{1 \dagger}$, O. Andréoletti ${ }^{4}$, I. Lantier ${ }^{3}$, C. Rossignol $^{3}$, A. Bossers $^{5}$, \\ J. G. Jacobs' ${ }^{5}$, N. Hunter ${ }^{2}$, M. H. Groschup ${ }^{1}$, F. Lantier ${ }^{3}$ and J. P. M. Langeveld ${ }^{5^{*}}$
}

\begin{abstract}
Breeding towards genetic resistance to prion disease is effective in eliminating scrapie. In sheep, classical forms of scrapie have been eradicated almost completely in several countries by breeding programs using a prion protein (PrP) gene (PRNP) amino acid polymorphism. For goats, field and experimental studies have provided evidence for several amino acid polymorphisms that are associated with resistance to scrapie, but only limited data are available concerning the susceptibility of caprine PRNP genotypes to BSE. In this study, goat kids representing five PRNP genotypes based on three polymorphisms (M142, Q211 and K222 and the wild type I142, R211 and Q222) were orally challenged with bovine or goat BSE. Wild type goats were killed with clinical signs between 24-28 months post inoculation (mpi) to both challenges, and goats with genotype R/Q211 succumbed between 29-36 mpi. I/M142 goats developed clinical signs at 44-45 mpi and M/M142 goats remained healthy until euthanasia at 48 mpi. None of the Q/K222 goats showed definite clinical signs. Taken together the highest attack ratios were seen in wild type and R/Q211 goats, and the lowest in I/M142, M/M142 and Q/K222. In all genotype groups, one or more goats remained healthy within the incubation period in both challenges and without detectable PrP deposition in the tissues. Our data show that both the K222 and M142 polymorphisms lengthen the incubation period significantly compared to wild type animals, but only K222 was associated with a significant increase in resistance to BSE infection after oral exposure to both BSE sources.
\end{abstract}

\section{Introduction}

Prion diseases or transmissible spongiform encephalopathies (TSEs) are caused by a unique infectious agent ("prion") characterised by an entirely proteinaceous nature with apparent absence of functional nucleic acids $[1,2]$. Disease transmission is possible within and between mammalian host species. Pivotal for transmissibility is the host's prion protein $(\operatorname{PrP})$ that in its normal state is a cell membrane protein $\left(\mathrm{PrP}^{\mathrm{C}}\right)$ to which recently several potential functions have been ascribed either in receptor mediation or immunological quiescence [3, 4].

\footnotetext{
${ }^{*}$ Correspondence: jan.langeveld@wur.nl

${ }^{\dagger}$ C. Fast, W. Goldmann, P. Berthon and K. Tauscher contributed equally to the study

${ }^{5}$ Wageningen BioVeterinary Research, Wageningen University \& Research, Houtribweg 39, 8221RA Lelystad, The Netherlands

Full list of author information is available at the end of the article
}

In prion diseases $\operatorname{PrP}^{\mathrm{C}}$ is converted into a stable "pathological" conformer $\left(\mathrm{PrP}^{\mathrm{Sc}}\right)$, which is the diagnostic disease marker detectable in immunohistochemistry by its disease associated deposition patterns $\left(\operatorname{PrP}^{\mathrm{D}}\right)$ and biochemically by its aggregation properties and protease resistance of its C-terminal core region $\left(\mathrm{PrP}^{\mathrm{res}}\right)$ [5-7].

The emergence of bovine spongiform encephalopathy (BSE) in cattle and its subsequent transmission to humans as variant Creutzfeld-Jakob disease (vCJD) has proven that prion diseases represent a threat for man and other mammalian species $[8,9]$. Goats represent the only other domestic ruminant species to be affected by BSE under field conditions [10-12]. Furthermore, goats are susceptible to classical scrapie although the disease occurs in Europe generally at 2-3 times lower prevalence than in sheep [13]. Susceptibility to TSE infection in sheep and goats has a strong genetic component that 
potentially allows selection by breeding for resistance. The basis for this selection is the polymorphic character of the PrP amino acid sequence, because some of these $\operatorname{PrP}$ variants do not convert easily to $\operatorname{PrP}^{\mathrm{Sc}}$ [14]. Breeding towards resistance has been successfully accomplished for sheep in some EU countries using the Q171R amino acid polymorphism as selection target, helped by the fact that the R171 allele appears to be dominant with almost complete protection to natural scrapie in R/R171 homozygotes as well as in Q/R171 heterozygotes [13, 15, $16]$.

A review of genotype surveys conducted worldwide revealed that on average almost $40 \%$ of goat PRNP sequences showed some variation of the amino acid sequence compared to the wild type $[17,18]$. Case control studies have narrowed the potential candidates for resistance-associated polymorphisms to six amino acid changes: M142, S146, D146, H154, Q211 and K222 (wild type I142, N146, R154, R211 and Q222) [19-25]. It should be noted that wild type and variant PRNP alleles vary in codon 240 either encoding S240 or P240. While the wild type allele appears to split on average equally between S240 and P240 sequences, some of the variant alleles have so far only been observed in one combination, for example K222-S240. Association of codon 240 with TSE resistance is most likely weak or absent [19-21, 26]. The occurrence and frequencies of these PRNP alleles are breed and region dependent [27-29]. The strong genetic resistance to classical scrapie conferred by the K222 allele was corroborated by studies in goats using intracerebral and oral scrapie challenges with isolates from Italy, the USA or France [30-32].

We have previously published an interim report on a study of an oral challenge in goats with caprine BSE [33]. Here we report the final and full results of this study in which caprine and bovine BSE isolates were inoculated orally into goats of five different genotypes which were homozygous wild type (wt/wt) and M/M142 or heterozygous I/M142, R/Q211 and Q/K222. The data provide convincing evidence that the K222 allele is the strongest protective factor in goats against BSE.

\section{Materials and methods}

\section{Animals}

Three different laboratories were involved in the challenges to exploit the available space: INRA Nouzilly, France (lab1), The Roslin Institute, UK (lab2) and FLI, Germany (lab3). Animal experimentation was performed according to European directive 2010/63/EU as well as in compliance with the respective national legislations in these countries (reference number for Germany LALLF
7221.3-2.5-001/05, Animal \& Scientific Procedures Act 1986, UK). At INRA (France), all experiments were conducted in accordance with the guidelines of the European Council Directive (86/609) and approved by the local ethical committee; the animals were kept in Biosafety Level 3 confined housing (PFIE, UE-1277, INRA Centre Val de Loire, Nouzilly, France). Goat kids of different breeds were obtained after weaning from the following sources: for lab1 and lab3 through Francis Barillet (goat production at INRA Centre Val-de-Loire in Bourges Experimental Unit, INRA division of Animal Genetics) and for lab2 through acquisition from UK holdings and through artificial insemination of females from the Roslin Institute. The animals belonged to the following breeds: Alpine, Saanen, Boer, Toggenburg and their crosses. Animals had been bred and selected based on their PRNP genotype, they were either I/M142, M/M142, R/Q211, Q/K222 or homozygous wild type for any of these codons (wt/wt). In total 129 animals were used in this study (Table 1).

\section{Challenge and disease monitoring}

Bovine and goat BSE brain materials were derived from clinically and $\mathrm{PrP}^{\mathrm{Sc}}$ - positive confirmed cases. The cattle BSE homogenate for first passage was derived from a pool of two clinically affected UK BSE cases supplied by the VLA (now APHA, Weybridge, UK) (Table 1). The goat BSE homogenate for second passage was pooled brain material derived from three clinically and $\mathrm{PrP}^{\mathrm{Sc}}$ positive animals of $\mathrm{wt} / \mathrm{wt}$ genotype following intracerebral challenge with cattle BSE [34]. Animals were orally challenged twice with $1 \mathrm{~g}$ of bovine BSE in $10 \mathrm{~mL}$ physiological saline solution with a 2 weeks interval (lab1, lab2) or only once with $1 \mathrm{~g}$ of goat BSE in $5 \mathrm{~mL}$ saline due to the lower amount of goat brain material available (lab2, lab3). During the incubation period, blood samples (lab1-3) as well as tonsil (lab1-3) and rectal (lab3) biopsies were taken on a regular scheme (Additional file 1). One to three animals per genotype were euthanized at first at pre-defined time points during the observation period. In addition goats were killed after showing consistently clinical signs typical for BSE (i.e. neurological disorders such as abnormalities in sensation and movement) or due to animal welfare reasons other than BSE. The last goats were killed due to animal welfare reasons other than BSE at $81 \mathrm{mpi}$. Seven unchallenged wt/ wt goats (lab1 two, lab2 three, and lab3 two) and one unchallenged R/Q211 (lab3) shared the pens with challenged animals between 13 and 47 months of the inoculation period to control for horizontal transmission. At necropsy a wide range of tissue samples were harvested under TSE-sterile conditions. 
Table 1 Experimental setup in the different labs performing the goat oral challenge

\begin{tabular}{|c|c|c|c|c|}
\hline & lab1 & \multicolumn{2}{|c|}{ lab2 } & lab3 \\
\hline $\begin{array}{l}\text { Experimental } \\
\text { setup }\end{array}$ & \multicolumn{2}{|c|}{$1^{\text {st }}$ passage } & \multicolumn{2}{|c|}{$2^{\text {nd }}$ passage } \\
\hline Inoculum & \multicolumn{2}{|c|}{ Cattle BSE (UK) } & \multicolumn{2}{|c|}{ Goat BSE (gBSE-P12; wt/wt) } \\
\hline Inoculation & \multicolumn{2}{|c|}{$\begin{array}{c}2 \times 1 \mathrm{~g} / \text { goat, interval of } \\
15 \text { days }\end{array}$} & \multicolumn{2}{|c|}{$1 \times 1$ g/goat } \\
\hline $\begin{array}{l}\text { Mode of } \\
\text { inoculation }\end{array}$ & \multicolumn{3}{|c|}{$10 \mathrm{~mL} /$ goat, (1:10 in glucose) } & $\begin{array}{c}5 \mathrm{~mL} / \text { goat, }(1: 5 \\
\text { in saline })\end{array}$ \\
\hline $\begin{array}{l}\text { Age at } \\
\text { inoculation }\end{array}$ & $3-4$ months & 6-9 months & 6-9 months & 6-7 months \\
\hline \multirow[t]{2}{*}{ Goat breed } & Alpine, Saanen & \multicolumn{2}{|c|}{ Saanen, Boer, Toggenburg } & Alpine-Saanen \\
\hline & \multicolumn{4}{|c|}{ Number of goats and genotype } \\
\hline Total & 38 & 27 & 24 & 40 \\
\hline wt/wt & 12 & 12 & 11 & 15 \\
\hline I/M142 & & 10 & 11 & \\
\hline $\mathrm{M} / \mathrm{M} 142$ & & 4 & & \\
\hline $\mathrm{R} / \mathrm{Q} 211$ & 12 & & & 11 \\
\hline Q/K222 & 12 & & & 11 \\
\hline Controls & 2 (wt/wt) & 1 (wt/wt) & $2(w t / w t)$ & $\begin{array}{c}3 \text { (2 wt/wt, } 1 \\
\mathrm{R} / \mathrm{Q} 211)\end{array}$ \\
\hline
\end{tabular}

BSE, bovine spongiform encephalopathy; UK, United Kingdom; gBSE-P12, identification number of goat brain pooled homogenate; wt/wt, homozygous wild type; $\mathrm{I} / \mathrm{M} 142$, heterozygous isoleucine/methionine genotype at codon 142; M/M142, homozygous methionine genotype at codon 142; R/Q211, heterozygous arginine/ glutamine genotype at codon $211 ; \mathrm{Q} / \mathrm{K} 222$, heterozygous glutamine/lysine genotype at codon 222.

\section{Antibody sources}

PrP specific antibodies used and their sources were: Bar224, Sha31 and SAF84 [35], 6C2 and 12B2 [36, 37], R145 [38], F99/97.6.1 [39], P4 and L42 [40], and 6H4 [41]. R145 and F99/97.6.1 were epitope mapped by Pepscan analysis to the respective ovPrP sequences 223RESQ226 and 221YQRE224 following published methods [42].

\section{Histology and immunohistochemistry}

The formalin fixed tissue samples were hematoxylin and eosin (H\&E) stained and immunohistochemically (IHC) processed with well established procedures using $\operatorname{PrP}$ specific antibodies [38, 43, 44]. Methodological details are summarized in Additional file 1.

\section{Biochemical analysis for scrapie-BSE discrimination and in-depth TSE typing}

Brain stem samples of all animals were further examined by Western blot for discrimination between classical scrapie and BSE (Additional file 1) as described before [44-47]. Furthermore for in-depth TSE typing, triplex Western blot (triplex-WB) analyses were carried out as described before, using a mix of three antibodies, 12B2, Sha31 and either SAF84 or F99 after first immunocomplexing these respectively with Zenon labels Alexa 647, 555, and 488 [48]. These antibodies are markers: (1) for presence of the N-terminal epitope (12B2) typical for classical scrapie but absent in classical BSE, and CH1641 scrapie, (2) the core region of $\mathrm{PrP}^{\text {res }}$ (Sha31), and (3) the presence of a second $\mathrm{PrP}^{\text {res }}$ population covering the C-terminal PrP region between the Sha31 epitope (sequence 148YEDRYYRE155, ovine numbering) and the C-terminus of mature $\mathrm{PrP}$ which is only recognized by antibodies like SAF84 and F99 (respective epitope sequences 166YRPVDQY171 and 221YQRE224) and which fragment is characteristic for $\mathrm{CH} 1641$ scrapie and H-type BSE. For comparison, reference samples used were: C-type, H-type and L-type BSE from cattle, and small ruminant BSE, classical scrapie, and CH1641 scrapie (sheep and/or goat) were used as in previous publications $[31,49]$. 


\section{Mouse bioassay}

In lab1 and lab3 mouse bioassays were performed at 6 and $12 \mathrm{mpi}$ with different tissues taken from respectively cattle BSE and goat BSE infected goats to test for the eventual presence of infectivity in the early stage of disease incubation. In doing so transgenic mice overexpressing ovine (in lab1 Tg338 and in lab3 TgshpIX) and bovine PrP (in lab $1 \mathrm{Tg} 110$ ) were used. All mouse lines are known to be highly sensitive for the detection of prion infectivity of different origin including BSE ( $\operatorname{Tg} 110$ in [33], the $\operatorname{Tg} 338$ and Tgshp IX in preparation by Nonno et al.). Additionally end-point titration experiments with a goat BSE isolate were done using $\operatorname{Tg} 110$ [33] and TgshpIX mice (lab 3 , unpublished results), but data are not included here. The mice were intracerebrally inoculated (6-15 mice per sample, depending of the different lab schedules routinely done in France and Germany) with $20-30 \mu \mathrm{L}$ of a 10\% tissue homogenate diluted in physiological saline $[45,50$, 51]. Subsequently all mice were clinically checked at least twice a week and either sacrificed due to animal welfare reasons or after $730 \mathrm{dpi}$ at the latest. The mouse brains were subsequently tested for the presence of proteinase $\mathrm{K}$ resistant $\operatorname{PrP}^{\mathrm{Sc}}\left(\operatorname{PrP}^{\text {res }}\right)$ by Western blot [44].

\section{Statistical analysis}

Differences in incubation period lengths were analysed for statistical significance with Student's T test and significance for differences in distribution between healthy and disease animals by challenge and genotype groups were analysed with Fisher's Exact Test for a $2 \times 2$ Contingency Table with two-tailed probability (p).

\section{Results}

Goat challenge results were classified in four health stage categories: (a) clinical-when consistent neurological signs pointing to a BSE infection were observed, (b) late preclinical-when no obvious clinical signs were observed but the animal appeared post mortem positive by IHC in the central nervous system (CNS), (c) early preclinical-when animals showed positivity by IHC in peripheral tissues but not yet in the CNS, and (d) healthy-without any of these markers. The occurrence of these categories in the time line after challenge of individual goats with their genotypes can be viewed in Additional file 2. Additionally, the time points mentioned below refer to the date of necropsy and subsequent prove of $\mathrm{BSE}$ infection by the detection of $\operatorname{PrP}^{\mathrm{D}}$ in the brain stem. However, it has to be born in mind that some of these goats displayed the first clinical signs up to 6-12 weeks before necropsy.

\section{Goat challenges: first passage (bovine BSE)}

Sixty-two animals were challenged with bovine BSE in lab1 and lab2. The goats were in five PRNP genotype groups: wt/wt $(\mathrm{n}=24), \mathrm{I} / \mathrm{M} 142(\mathrm{n}=10), \mathrm{M} / \mathrm{M} 142$ $(\mathrm{n}=4), \mathrm{R} / \mathrm{Q} 211(\mathrm{n}=12)$ and $\mathrm{Q} / \mathrm{K} 222(\mathrm{n}=12)$. Three unchallenged wild type animals were kept as contact controls (Table 1). In total 22 animals were affected by BSE, while 40 goats and the controls remained completely negative with observation periods up to 48 months postinoculation (mpi) (Figure 1).

Clinical signs appeared in ten goats: five wt/wt goats at 25/26 mpi, three R/Q211 animals between 28-33 mpi

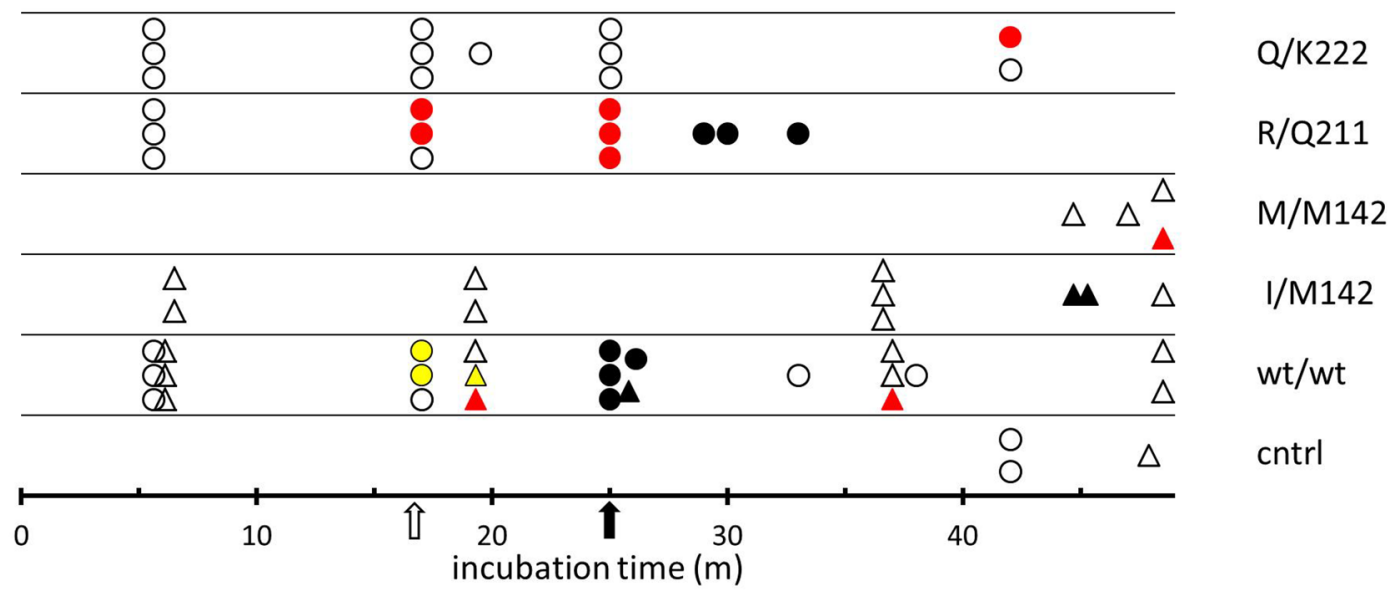

Figure 1 Overview of the results of challenge with bovine BSE ( $1^{\text {st }}$ passage) in goats with five different genotypes. Each symbol represents an individual goat. Symbol colours: empty, yellow, red and black represents TSE negative, preclinical PrPD (positivity in peripheral sites), late preclinical (PrPD positivity in CNS, no clear clinical signs) and clinical cases (these are also PrPD positive in periphery and CNS). Symbol shapes represent location of experiment: circles, lab 1, triangles lab 2 (see also "Materials and methods" section). The two arrows under the X-axis: open and bold indicate respectively the month after inoculation at which respectively the first preclinical and clinical cases were observed. 
and even later at 44/45 mpi in two I/M142 goats. All clinically affected animals were $\operatorname{PrP}^{\mathrm{D}}$ positive by immunohistochemistry (IHC) in the central nervous system (CNS) and peripheral tissues in various combinations (see below).

A further nine animals were in a late preclinical state at necropsy and revealed $\operatorname{Pr}^{\mathrm{D}}$ in brain stem as shown by IHC and/or biochemical analysis, but none of these goats showed clearly identifiable clinical signs typical for BSE. This group included two wt/wt goats sacrificed at 19 and $36 \mathrm{mpi}$, five R/Q211 goats sacrificed at $17(\mathrm{n}=2)$ and 25 $(\mathrm{n}=3) \mathrm{mpi}$, one $\mathrm{Q} / \mathrm{K} 222$ goat killed at $43 \mathrm{mpi}$ and one $\mathrm{M} / \mathrm{M} 142$ goat killed at $48 \mathrm{mpi}$.

Another three wt/wt goats were in an early preclinical state at $17(\mathrm{n}=2)$ and $19(\mathrm{n}=1)$, revealing weak amounts of $\operatorname{PrP}^{\mathrm{D}}$ in different peripheral tissues only (see below). Samples from CNS and spleen from nine (3 wt/wt, $3 \mathrm{R} / \mathrm{Q} 211,3 \mathrm{Q} / \mathrm{K} 222$ ) healthy, BSE negative goats, which were culled at $6 \mathrm{mpi}$ as part of the pathogenesis study, were examined by mouse bioassay using transgenic mouse lines $\operatorname{Tg} 110$ and $\operatorname{Tg} 338$. None of these mice showed clinical or pathological signs of a TSE infection.

The 40 non-affected animals were euthanized at various time points with the longest survival times in the different genotypes as follows: $48 \mathrm{mpi}$ for $2 \mathrm{wt} / \mathrm{wt}$, one I/M142 and one M/M142, and 43 mpi for one Q/K222 goat.

Because some animals were removed from the challenge groups at pre-defined post-inoculation times, attack ratios for preclinical, late preclinical and clinical animals $12 \mathrm{mpi}$ and later were only considered for estimation. These ratios were not less than $56 \%$ in wt/ wt, $25 \%$ in I/M142 goats, $25 \%$ in M/M142, $89 \%$ in R/ Q211, and 11\% in Q/K222 goats (Table 2). These values decreased for four genotypes when only clinical positive animals were included: $28 \%$ in wt/wt, $0 \%$ in $\mathrm{M} / \mathrm{M} 142$, $33 \%$ in $\mathrm{R} / \mathrm{Q} 211$ and $0 \%$ in $\mathrm{Q} / \mathrm{K} 222$ goats.

Table 2 Data concerning the effectiveness of the oral challenges in goats with bovine ( $1^{\text {st }}$ passage) and caprine $\left(2^{\text {nd }}\right.$ passage) BSE

\begin{tabular}{|c|c|c|c|c|c|c|c|c|c|c|c|c|c|c|}
\hline \multirow[t]{2}{*}{ Genotype } & \multicolumn{5}{|c|}{ Numbers } & \multicolumn{8}{|c|}{ Numbers from $12 \mathrm{mpi}$} & \multirow{2}{*}{$\begin{array}{l}\text { Inc. time clinical, mpi } \\
\pm S D(n)\end{array}$} \\
\hline & Total & \multicolumn{2}{|c|}{ Before $12 \mathrm{mpi}$} & \multicolumn{2}{|c|}{ After $12 \mathrm{mpi}$} & \multicolumn{2}{|c|}{ Pre-clinical } & \multicolumn{2}{|c|}{ Late preclinical } & \multicolumn{2}{|c|}{ Clinical } & \multicolumn{2}{|c|}{$\begin{array}{l}\text { Attack ratios affected/ } \\
\text { total }(\%)+\text { significance }\end{array}$} & \\
\hline \multicolumn{15}{|l|}{ bovBSE } \\
\hline wt & 24 & 6 & & 18 & & 3 & & 2 & & 5 & & 10/18 (56\%) & & $25.2 \pm 0.4(5)$ \\
\hline I/M142 & 10 & 2 & & 8 & & 0 & & 0 & & 2 & & $2 / 8(25 \%)^{* *}$ & & $44.5 \pm 0.7(2)$ \\
\hline M/M142 & 4 & 0 & & 4 & & 0 & & 1 & & 0 & & $1 / 4(25 \%)$ & & NA \\
\hline $\mathrm{R} / \mathrm{Q} 211$ & 12 & 3 & & 9 & & 0 & & 5 & & 3 & & 8/9 (89\%) & & $30.7 \pm 2.1(3)$ \\
\hline $\mathrm{Q} / \mathrm{K} 222$ & 12 & 3 & & 9 & & 0 & & $1^{\mathrm{b}}$ & & 0 & & $1 / 9(11 \%)^{* *}$ & & NA \\
\hline \multicolumn{15}{|l|}{ gtBSE } \\
\hline wt & 26 & 6 & & 20 & & 2 & & 3 & & 5 & & $10 / 20(50 \%)$ & & $25.6 \pm 1.5(5)$ \\
\hline I/M142 & 11 & 3 & & 8 & & 0 & & 0 & & 0 & & $0 / 8(0 \%)^{*}$ & & NA \\
\hline $\mathrm{R} / \mathrm{Q} 211$ & 11 & 4 & & 7 & & 1 & & 0 & & 3 & & $4 / 7(57 \%)$ & & $34.3 \pm 1.5(3)$ \\
\hline $\mathrm{Q} / \mathrm{K} 222$ & 11 & 3 & & 8 & & 0 & & $1^{c}$ & & 0 & & $1 / 8(13 \%)^{c *}$ & & NA \\
\hline \multirow[t]{2}{*}{ Genotype } & \multirow[t]{2}{*}{ Total } & \multicolumn{5}{|l|}{$\mathrm{mpi}$} & \multicolumn{6}{|c|}{ Numbers from $12 \mathrm{mpi}$} & \multirow{2}{*}{\multicolumn{2}{|c|}{$\begin{array}{l}\text { Inc. time clinical, mpi } \\
\pm S D(n)\end{array}$}} \\
\hline & & $1^{\text {st }}$ clin case & $\begin{array}{l}\text { Last } \\
\text { case }\end{array}$ & $\begin{array}{l}\text { st clin } \\
\text { se }\end{array}$ & Pre & -clinical & $\begin{array}{l}\text { Late } \\
\text { cal }\end{array}$ & e preclini- & & nical & $\begin{array}{l}\text { Atta } \\
\text { tota }\end{array}$ & $\begin{array}{l}\text { ck ratios affected/ } \\
\text { l (\%) + significance }\end{array}$ & & \\
\hline \multicolumn{15}{|c|}{ Combined challenges } \\
\hline wt & 50 & 24 & 28 & & 5 & & 5 & & 10 & & $20 / 3$ & $8(53 \%)$ & 25.4 & $\pm 1.1(10)$ \\
\hline I/M142 & 21 & 44 & 45 & & 0 & & 0 & & 2 & & $2 / 16$ & $(13 \%)^{* *}$ & 44.5 & $\pm 0.7(2)$ \\
\hline M/M142 & 4 & NA & NA & & NA & & NA & & NA & & NA & & NA & \\
\hline $\mathrm{R} / \mathrm{Q} 211$ & 23 & 28 & 36 & & 1 & & 5 & & 6 & & $12 / 1$ & $6(75 \%)$ & 32.5 & $\pm 2.6(6)$ \\
\hline Q/K222 & 23 & 43 & NA & & 0 & & 2 & & 0 & & $2 / 17$ & $(12 \%)^{* * *}$ & NA & \\
\hline
\end{tabular}

NA, not applicable.

a Statistical data: compared to the wild type group. Fisher's exact test, ${ }^{*},{ }^{*}$, and ${ }^{* * *}$ respectively $p<0.05, p<0.01, p<0.001$.

b This Q/K222 goat was CNS- and muscle-positive.

c One Q/K222 case was CNS-positive, and psoas-muscle-positive but by mouse bioassay (Tg110) only [33]. If considered negative (by IHC) this group was statistically positive compared to the wild type group $(p<0.05)$. 


\section{Goat challenges: second passage (goat BSE)}

Fifty-nine goats were challenged with goat BSE in lab 2 and lab 3. They were in four PRNP genotype groups: wt/ wt $(\mathrm{n}=26), \mathrm{I} / \mathrm{M} 142(\mathrm{n}=11), \mathrm{R} / \mathrm{Q} 211(\mathrm{n}=11)$, and Q/ K222 $(\mathrm{n}=11)$ (Table 1). Four wildtype and one R/Q211 animals were kept as unchallenged contact controls. In total 15 animals were affected by a BSE infection, and 44 goats and the controls remained completely negative within the observation period up to $81 \mathrm{mpi}$ (Figure 2).

Clinical signs appeared in eight goats: five wt/wt goats between 24 and $28 \mathrm{mpi}$, and three R/Q211 animals between 33-36 mpi. All clinically affected animals were $\operatorname{PrP}^{\mathrm{D}}$ positive by IHC in the CNS and in peripheral tissues in various combinations (for details see below).

Additional four animals were in a late preclinical state at necropsy revealing $\operatorname{PrP}^{\mathrm{D}}$ or infectivity in brain stem as shown by IHC. None of these goats showed clinical signs typical for BSE. This group included three wt/wt goats at 19,24 and $36 \mathrm{mpi}$ as well as one Q/K222 goat at $45 \mathrm{mpi}$ (infectivity data from this goat are published in [33]).

Two wt/wt goats (12 and $25 \mathrm{mpi}$ ) and one R/Q211 goat (12 mpi) were in an early preclinical state, revealing weak amounts of $\operatorname{PrP}^{\mathrm{D}}$ in peripheral tissues only (for details see below). None of the I/M142 and Q/K222 goats showed clinical TSE signs.

Various samples from CNS (brain stem) and peripheral tissues (including samples from gut, lymphoreticular tissues as well as autonomous nervous system) from two healthy and BSE negative wt/wt goats, which were culled at $12 \mathrm{mpi}$ as part of the pathogenesis study, were examined by mouse bioassay using transgenic mouse lines TgshpIX. None of these mice showed clinical or pathological signs of a TSE infection.
The 44 non-affected animals were euthanized at various time points with the longest survival times in the different genotypes as follows: $81 \mathrm{mpi}$ for one wt/wt and one Q/K222 goat, $47 \mathrm{mpi}$ for three I/M142 goats and 77 mpi for a R/Q211 goat.

Similar to the first passage BSE study, challenged animals $12 \mathrm{mpi}$ and later were only considered for estimation of attack ratios. These attack ratios for preclinical, late preclinical and clinical animals together were not less than $50 \%$ in wt/wt, $0 \%$ in I/M142 goats, $57 \%$ in R/ Q211, and 13\% in Q/K222 goats (Table 2). Including only clinically positive animals reduced these values to $25 \%$ in $\mathrm{wt} / \mathrm{wt}, 43 \%$ in R/Q211 and $0 \%$ in Q/K222 goats, while I/ M142 goats remained unchanged.

\section{Statistical analysis}

There was no statistically significant difference in the wild type challenge outcomes regarding the number of affected animals or the incubation period length of clinically affected goats between the two BSE isolates or between the three different laboratories. The small number of goats developing clinical disease made it difficult to analyse differences of incubation period length between genotypes.

Considering the period from $12 \mathrm{mpi}$, where the first preclinical signs appeared in the challenges $(12 \mathrm{mpi}$, in a wt and a R/Q211 goat), till the end of the experiments (see Figure 2) there were significant differences in attack ratios between wild type and QK222 groups in both challenges if only based on IHC observations (Table 2). The attack ratios values between wt and IM142 goats in goat BSE challenge were also statistically different $(\mathrm{p}<0.05)$, but not after challenge with bovine BSE.

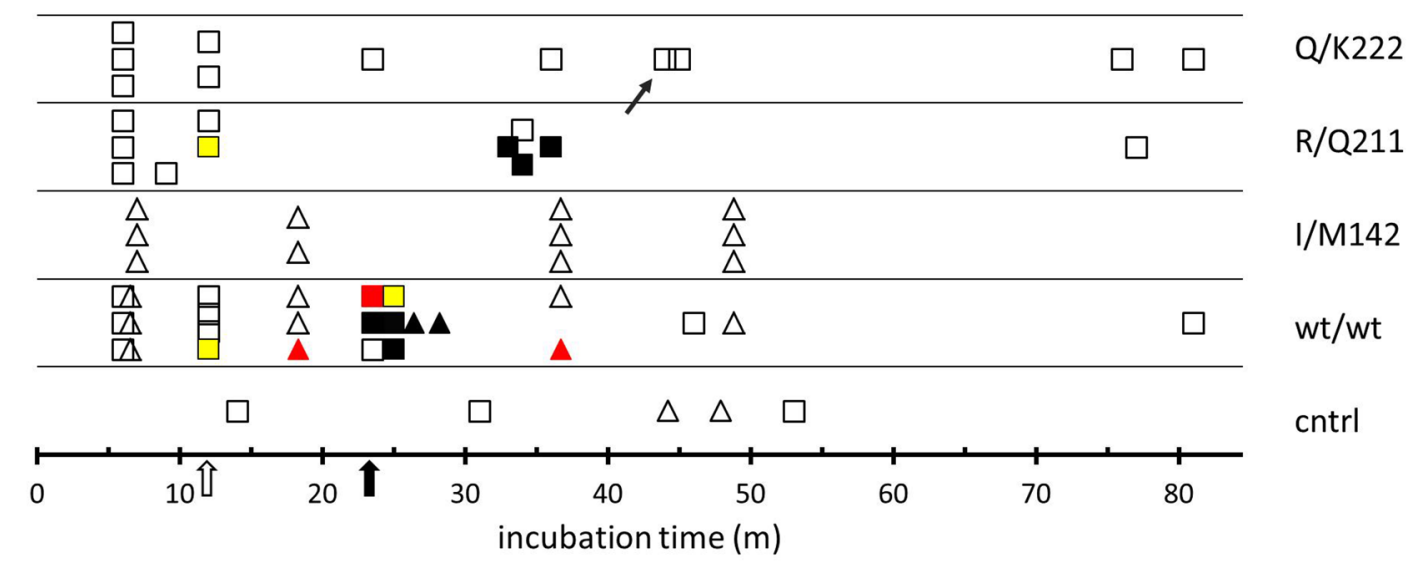

Figure 2 Overview of the results of challenge with goat BSE ( $=\mathbf{2}^{\text {nd }}$ passage) in goats with four different genotypes. Each symbol represents an individual goat. Symbol colours and arrows are explained in Figure 1. Symbol shapes represent the laboratory of experiment: triangles lab 2, and squares lab 3. The two arrows under the X-axis: open and bold indicate respectively the month after inoculation at which respectively the first preclinical and clinical cases were observed. Small arrow near one Q/K222 symbol is reflecting the animal previously found weakly brain (only) positive in infectivity testing in $\operatorname{Tg} 110$ mice [33]. 
Furthermore, differences became also apparent when the observation period was divided into early (12-30 $\mathrm{mpi}$ ) and late (> $30 \mathrm{mpi}$ ) phase and when both challenges were combined. In the early phase, infected animals were found only in wt/wt and R/Q211 goats at ratios of $18 / 25$ (72\%) and 7/11 (64\%), respectively; no infected animals occurred in genotypes I/M142 (0/4) and Q/K222 (0/10). The difference between group I (wt/wt, R/Q211) and group II (I/M142, Q/K222) was highly significant $(p<0.0001)$.

The late phase showed no significant difference between group I and group II and all genotypes had infected animals. After $30 \mathrm{mpi}, \mathrm{R} / \mathrm{Q} 211$ had a higher attack ratio of $5 / 7(71 \%)$ than either wt/wt with $2 / 12$ $(17 \%)$ or I/M142 with $2 / 12(p=0.03)$, but the difference to $\mathrm{Q} / \mathrm{K} 222(2 / 7)$ was not significant. While the minimal attack ratio for R/Q211 was unchanged between the two observation phases, wt/wt genotypes were significantly less likely to be infected $(p<0.002)$ once they had survived $30 \mathrm{mpi}$.

\section{Immunohistochemistry}

There were no distinct differences between the animals from the first and the second passage, therefore the immunohistochemical results will be presented for all groups together (see Additional files 3 and 4 for further details in respectively first and second passage results).

In total 30 goats revealed a clear $\operatorname{PrP}^{\mathrm{D}}$ accumulation in the brain stem (CNS positive cases in Figure 3A). The degree of $\operatorname{PrP}^{\mathrm{D}}$ deposition was associated with the clinical state of the animal. Thus, goats being in a late preclinical state showed a weak $(n=1)$, mild $(n=5)$ and moderate $(\mathrm{n}=4) \operatorname{PrP}^{\mathrm{D}}$ accumulation; only one $\mathrm{R} / \mathrm{Q} 211$ goat and one $\mathrm{Q} / \mathrm{K} 222$ goat (Figure $3 \mathrm{~B}$ ) were severely affected. In contrast, animals with clear clinical signs mostly exhibited a severe $\operatorname{PrP}^{\mathrm{D}}$ deposition $(\mathrm{n}=16)$ and more rarely a moderate accumulation $(\mathrm{n}=2)$. In most cases $\operatorname{Pr} \mathrm{P}^{\mathrm{D}}$ accumulation was widespread and involved the whole brain stem, both grey and white matter. In animals with only mild $\operatorname{PrP}^{\mathrm{D}}$ accumulation, the most prominent depositions were seen in the dorsal motor nucleus of the vagus
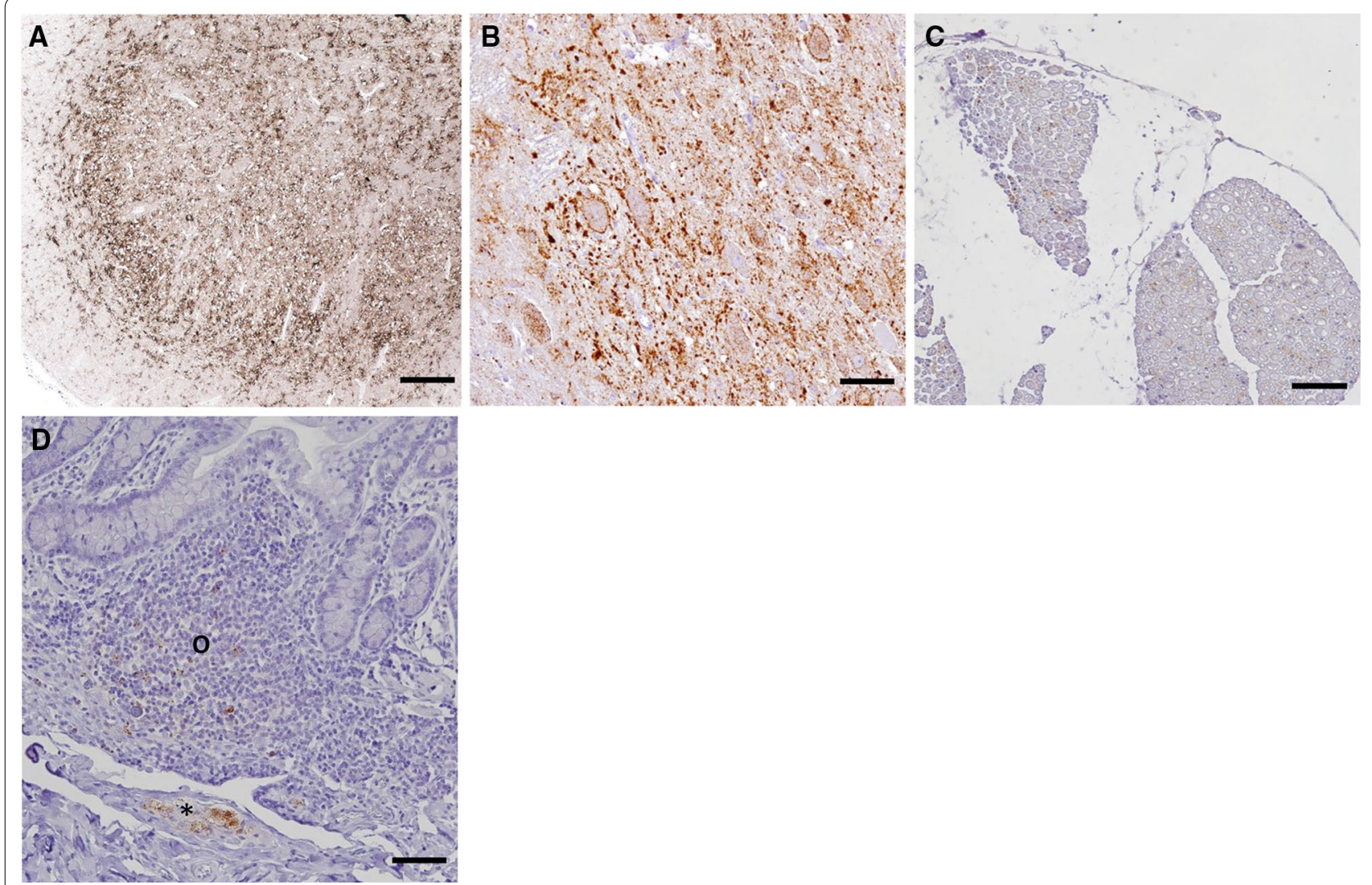

Figure 3 PrPD accumulation in central and peripheral nervous tissues of BSE infected goats. A Brain stem of a clinical goat BSE infected wt/wt goat, $24 \mathrm{mpi}$, showing a severe intra- and extracellular PrPD accumulation. Antibody 6C2, bar $50 \mu \mathrm{m}$. B Brain stem of the late preclinical cattle BSE infected Q/K222 goat, 43 mpi, showing a severe intra- and extracellular PrPD accumulation in the obex (DMNV). Antibody Bar224, bar $20 \mu m$. C Spinal nerve of a clinical cattle BSE infected wt/wt goat, 25 mpi, showing moderate intra-axonal and intraglial PrPD accumulation. Antibody Bar224, bar $100 \mu \mathrm{m}$. D lleum of a clinical cattle BSE infected wt/wt goat, $25 \mathrm{mpi}$, showing PrPD accumulation in neurons and glial cells of the enteric nervous system as well as intracellular in lymphoid cells of the ileal follicle. Antibody Bar224, bar $20 \mu \mathrm{m}$. 
nerve (DMNV), the nucleus of the solitary tract, cuneate nucleus, hypoglossal nucleus, spinal tract nucleus and the olivary nuclei. Using antibodies specific for the PrP C-terminus which detect $\mathrm{BSE}$ associated $\operatorname{Pr} \mathrm{P}^{\mathrm{D}}$ very well [52], intraneuronal, intraglial and cell-membrane-associated/extracellular fine to coarse $\operatorname{Pr} \mathrm{P}^{\mathrm{D}}$ accumulations were seen in all brain areas examined.

Several peripheral lymphoreticular tissue samples were analysed for $\operatorname{PrP}^{\mathrm{D}}$ accumulation, amongst them were mesenterial lymph nodes (MesLn), tonsil, ileum including Peyer's patches (PP), rectal follicles (RAMALT), celiac and mesenteric ganglion complex (CMGC), ileal and rectal enteric nervous system (ENS), vagal nerve and brachial plexus, along with different skeletal muscles (Mm. oculomotorius, psoas major and semitendinosus) (Figure 4). The analysis of five $\mathrm{wt} / \mathrm{wt}$ and one R/Q211 goat, which were negative in the brain stem, revealed $\operatorname{Pr} \mathrm{P}^{\mathrm{D}}$ accumulations in the tonsil $(\mathrm{n}=1)$, CMGC $(n=2)$ and ENS of the Ileum $(n=2)$ and in the ileal PP $(\mathrm{n}=1)$.

The ileal ENS was the most frequently positive site $(\mathrm{n}=8)$ in the twelve late preclinical goats, which had only mild to moderate amounts of $\operatorname{PrP}^{\mathrm{D}}$ in the brain stem. Only four animals showed a more widespread distribution of $\operatorname{PrP}^{\mathrm{D}}$ involving the rectal ENS $(\mathrm{n}=1)$, MesLn $(\mathrm{n}=2)$, ileal PP $(\mathrm{n}=2)$ and tonsil $(\mathrm{n}=2)$.

The positive $\mathrm{Q} / \mathrm{K} 222$ goat $(43 \mathrm{mpi}$ ) which was in a late preclinical state, showed a severe $\operatorname{Pr} \mathrm{P}^{\mathrm{D}}$ accumulation in the brain, but no involvement of the LRS (Figure 5). The only peripheral tissues slightly positive are rectal ENS and different muscles (M. oculomotorius, M. psoas major).

Clinically ill wt/wt and R/Q211 goats $(\mathrm{n}=16)$ with moderate up to severe $\operatorname{PrP}^{\mathrm{D}}$ accumulation in the brain

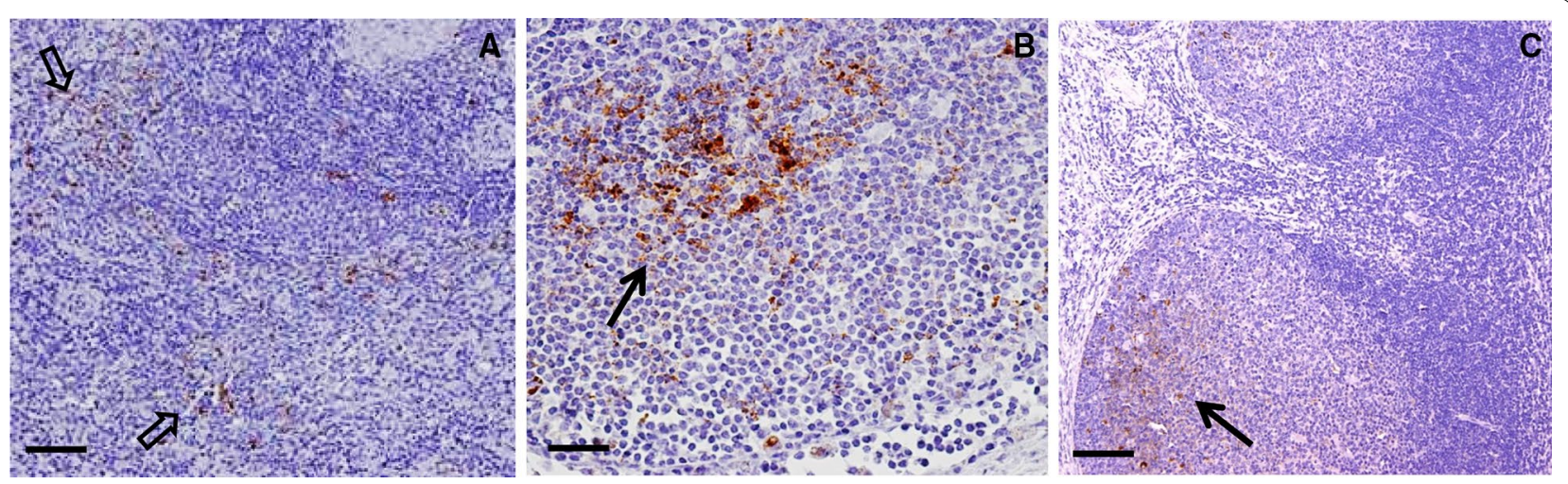

Figure 4 PrPD accumulation in lymphoreticular tissues of BSE infected goats. A Spleen of a clinical cattle BSE infected wt/wt goat, $26 \mathrm{mpi}$

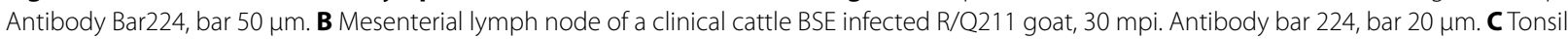
of a clinical cattle BSE infected I/M142 goat. Antibody R145, bar $50 \mu \mathrm{m}$. In all samples a mild to moderate PrPD accumulation in follicles and in the sinus of the spleen can be seen.

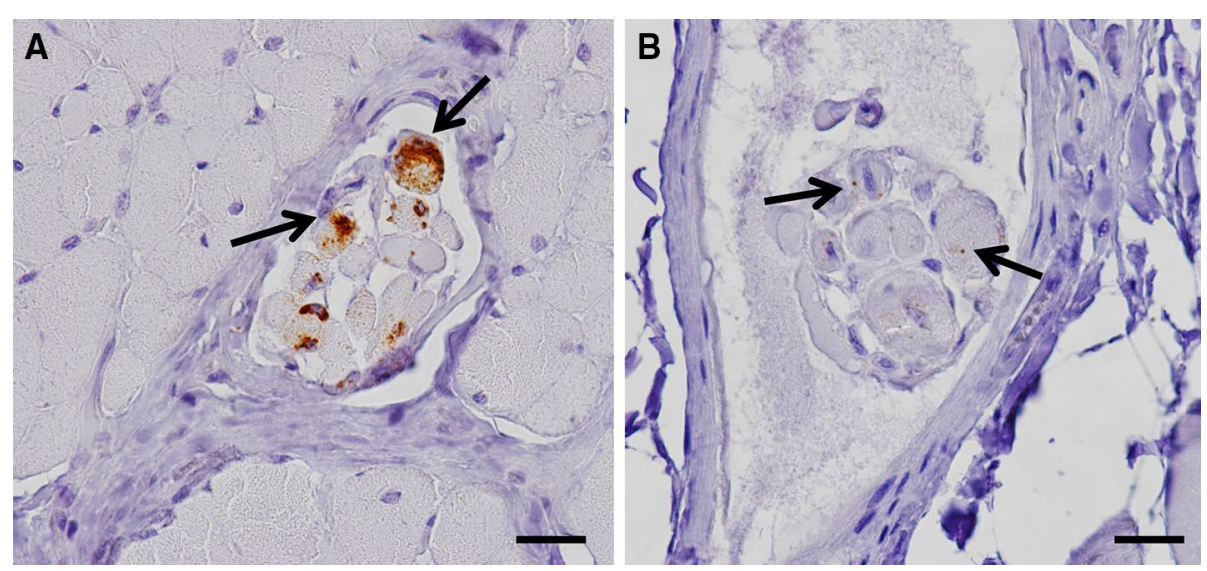

Figure 5 PrPD accumulation in different skeletal muscles. A Ocular muscle of a Q/R211 goat infected with cattle BSE showing PrPD accumulation in muscle spindles, 28 mpi. Antibody Bar224, bar $20 \mu \mathrm{m}$. B Psoas muscle of a Q/K222 goat infected with cattle BSE showing weak PrPD accumulation in muscle spindles, 43 mpi. Antibody Bar224, bar $20 \mu \mathrm{m}$. 
stem, revealed a more widespread distribution of $\operatorname{PrP}^{\mathrm{D}}$ in the LRS, ENS and different skeletal muscles with only five animals, in which $\operatorname{PrP}^{\mathrm{D}}$ accumulations were confined to the ENS and PP of the gut. Two animals even showed a positive reaction in peripheral nerves. More interestingly are the two I/M142 goats, both with severely affected brains. $\operatorname{PrP}^{\mathrm{D}}$ could be found in ileal ENS but not in the PP. Yet, one of these goats showed a mild $\operatorname{PrP}^{\mathrm{D}}$ deposition in tonsil follicles.

In tissues of the LRS the $\operatorname{Pr}^{\mathrm{D}}$ depositions were mostly confined to the follicles and rarely seen in the sinus. Reaction pattern seen is an intracellular fine to coarse granular staining in tingible body macrophages, follicular dendritic cells and few lymphocytes. Neuronal as well as glial cells were positive in the ENS (Figure 3), but in the CMGC only single neuronal cells showed a diffuse intracellular pattern. Single muscle spindles revealed a mild accumulation of $\operatorname{PrP}^{\mathrm{D}}$ (Figure 5).

\section{Discriminatory analysis and TSE typing}

Positivity in brain stem of all goats was analysed in the three laboratories, each with their own methodology to discriminate C-type BSE from classical scrapie (data not shown). Furthermore, in samples from goats of all genotypes and both passage numbers the type of TSE was studied in more detail using as reference samples bovine C-type, H-type and L-type BSE, ovine and caprine BSE, classical scrapie, and CH1641 scrapie (Figure 6A). The low presence of $12 \mathrm{~B} 2$ epitope (12B2/Sha31 signal ratio $<0.3$ ), the glycoprofile expressed as the ratio between mono- and diglycosylated $\operatorname{PrP}^{\mathrm{res}}(<0.4$, using glycoform fractions of total $\mathrm{PrP}^{\mathrm{res}}$ in the Sha31 epitope detection) and the presence of only a single $\operatorname{PrP}^{\text {res }}$ population pointed out that all positive samples did show the character of a C-type BSE infection (Figure 6B) [48, 49].

\section{Discussion}

This oral challenge study in goats elucidates the significant protection conferred by the $\mathrm{Q} / \mathrm{K} 222$ prion protein genotype against bovine and goat BSE infection administered through the oral route. There was no clear clinical case with this genotype in 17 challenged animals, although it has to be considered that both late-preclinical Q/K222 goat from the bovine and caprine BSE challenges might have developed clinical disease at some later stage. I/M142 heterozygous genotypes appeared to provide partial resistance, with two clinically positive cases. Including the M/M142 late-preclinical case, M142 is also clearly associated with lengthened incubation periods in BSE similar to scrapie challenges [31].

While the R/Q211 genotyped goats exhibited extended incubation periods of the clinical cases by about 5-9 months compared to the wild type goats in the two
BSE challenges, it appeared that there was also a difference in the susceptibility beyond 30 months post inoculation. In that late phase of the experiments, 2 out of 7 (29\%) animals survived BSE challenge in the R/Q211 group only whereas in the wild type group 10 out of 12 (83\%) animals showed no signs of BSE infection. Additional amino acid polymorphisms in PRNP can be excluded as reason for a survival difference between the two genotypes, therefore other genetic loci might be involved [53]. It is unlikely though to be solely due to breed or laboratory differences as discussed below.

This study has been conducted in three laboratories in parallel following similar protocols as much as possible, but with different breeds of different regional origins, and different age groups. Despite this set-up, which was logistically necessary to conduct a challenge study of 129 goat kids, significant differences were not observed between the laboratory groups as evidenced by a short mean incubation period and a narrow standard deviation $(25.4 \pm 1.1$, Table 2$)$ for the ten clinical cases of the wild type groups. This finding is supported by the fact that the tissue distribution did not reveal any remarkable deviations between the different laboratories.

The goat kids used here were aged 3-9 months at challenge, depending on the lab involved. Previous findings in sheep and goats suggest that to achieve the highest attack rates in oral challenge, administration before weaning was important, possibly due to the developmental stage of the Peyer's patches in the intestine [34, 54-56]. Although the exact response to challenge for the early age range was not known for goat kids, challenge of the kids before weaning was planned but could not be implemented due to logistic problems in animal movements. Nevertheless, the mean attack rate of $53 \%$ for all wild type animals in this study was distinctly higher than the $21 \%$ reported before for BSE challenged lambs of the 3-6 month age range [54]. It might reflect a higher intrinsic susceptibility of goats for oral challenge than sheep, which may also explain that BSE has only been identified in this species in natural conditions [10-12]. Taken together the data do not imply large variation due to selection of various age groups and breeds, but we cannot completely rule out that the sensitivity in the challenges of the five genotypes was reduced through an age effect.

Considering the successful transmissions in the different genotypes, our data showed that clinical disease was appearing first in the wt/wt goats at 24-28 mpi with no differentiation between cattle BSE (first passage) and caprine BSE (second passage). This is rather surprising, as it has been shown previously that interspecies transmission of TSEs results in long incubation periods, which usually shorten on further passages [57]. In particular, this result seems to contradict previous observations 
A

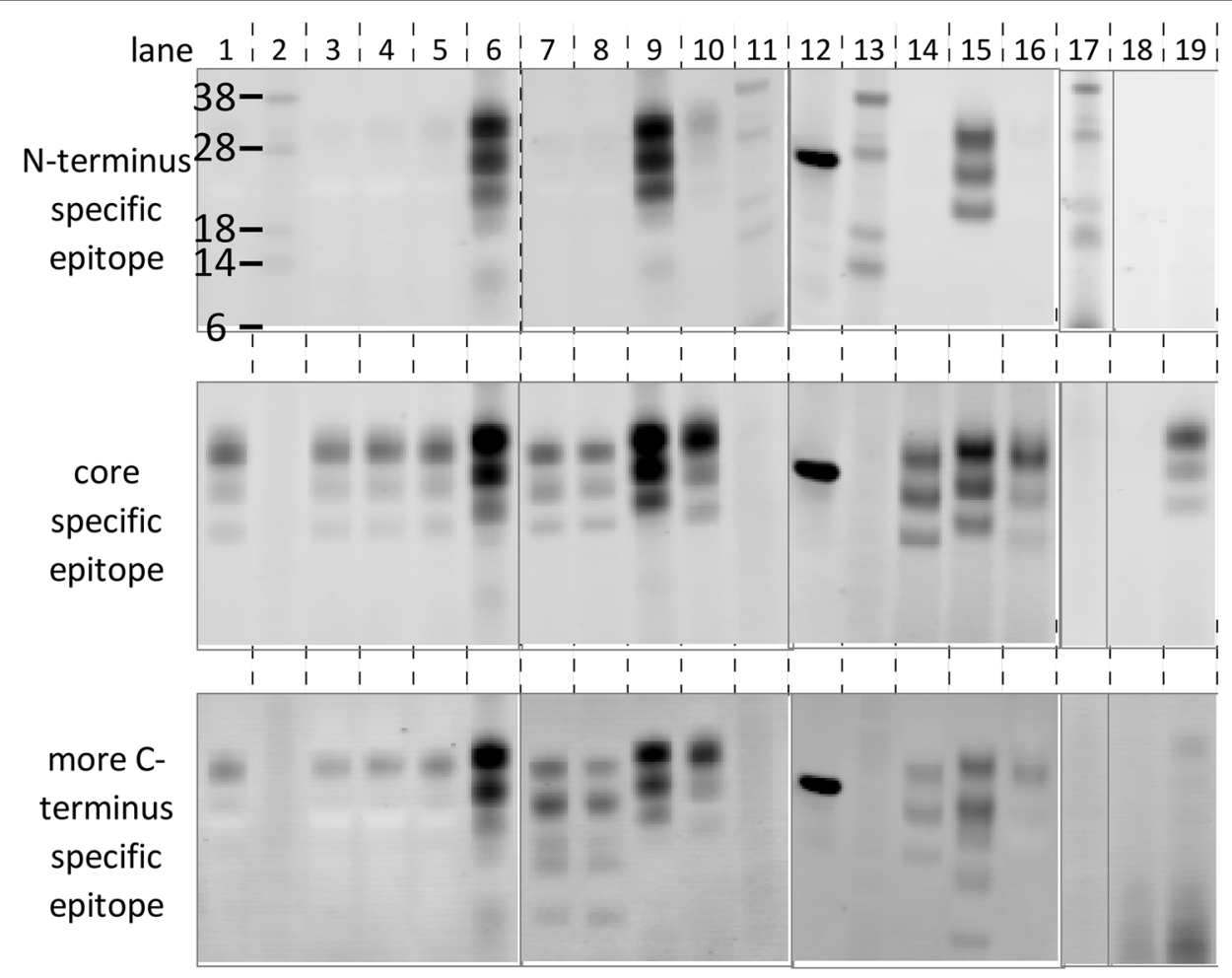

B
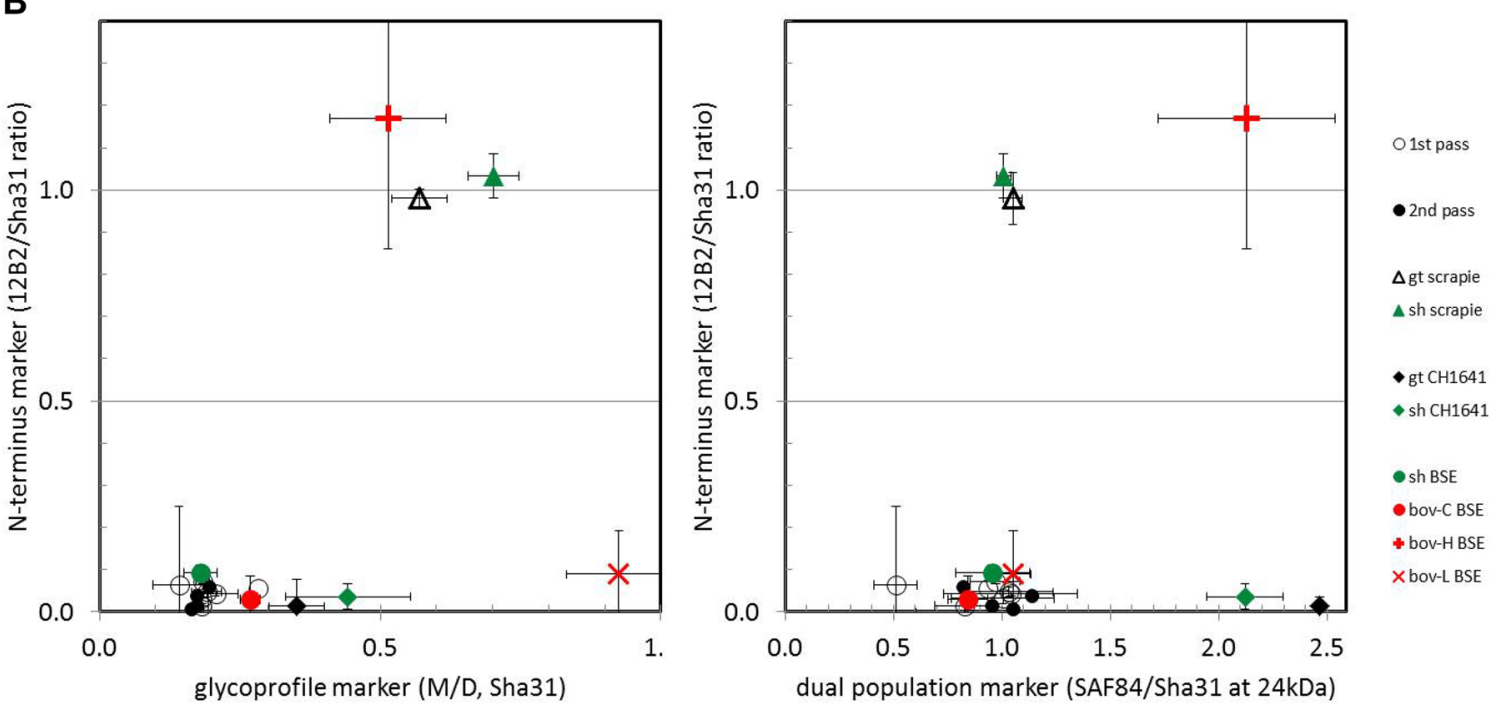

Figure 6 Western blot: triplex Western blot analysis of goat BSE brain stem samples with three antibodies on one membrane. Samples from orally challenged goats were analysed together with a set of different types of TSEs from goat, sheep and cattle to illustrate the classical BSE like character in the BSE-challenged goats. A Analysis with a mixture of three antibodies with different PrP specificities: N-terminus (12B2), core (Sha31) and C-terminus (SAF84, lanes 1-16; or F99, lanes 17-19). Lanes: 1, 3-5, 19 goat BSE material from respectively wt/wt $2^{\text {nd }}$ pass, R/Q211 $2^{\text {nd }}$ pass, wt/wt $2^{\text {nd }}$ pass, R/Q211 $2^{\text {nd }}$ pass, Q/K222 $1^{\text {st }}$ pass; lane 6, classical scrapie from i.c. challenged R/Q211 goat; lane 7, CH1641 scrapie from i.c. challenge in wt/wt sheep; lane 8 CH1641 scrapie from i.c. challenge in wt/wt goat; lane 9 natural scrapie from wt/wt sheep; lane 10 BSE from i.c. challenged wt sheep $1^{\text {st }}$ pass; lanes 14-16 respectively bovine C-type BSE, H-type BSE and L type BSE; lane 18, non-challenged goat material. Applied tissue equivalents were $0.5 \mathrm{mg}$, or (in lanes 3, 4, 14-16 and 19) $1 \mathrm{mg}$. Lanes 2, 11, 13, and 17, mol mass markers are indicated with their kDa; in lane 12, 15 ng rec-ovine PrP (wt). For linear epitope specificities of the antibodies, see paragraph Biochemical analysis of the Methods section. B Dot plots showing the TSE-type markers of individual samples derived from the antibody signals of PrPres in triplex-WB. Each symbol represents the average signal ratio obtained from a triplicate analysis per individual sample (bars for the standard deviations). All orally challenged goats yield a typical C-BSE pattern for the markers N-terminus, glycoprofile and dual population independent of genotype and passage $\left(1^{\text {st }}\right.$ or $\left.2^{\text {nd }}\right)$. The 12 analysed goat samples from the BSE challenges were: from $1^{\text {st }}$ pass two wt/wt, two I/M142, three R/Q211, and one Q/K222 cases (open circles); from $2^{\text {nd }}$ pass three $w t / w t$, and one R/Q211 cases (closed black circles). 
in transgenic mice expressing bovine PrP (Tg110), in which sheep- or goat-passaged BSE would lead to shorter incubation times than bovine BSE $[58,59]$. Differences between the two challenge conditions or titre of the challenge materials might have played a role. On the other hand, this phenomenon may well be the result of intracerebral administration in the mice, whereas BSE transmissibility through the oral route might be more dependent of host factors encountered in the LRS and ENS before entering the CNS [60]. However, a similar pattern of adaption has been observed in vitro by serial PMCA [60]. Overall, these results imply that passage of BSE through wt/wt and R/Q211 goats will not necessarily lead to a measurable adaptation of the BSE agent to goat. Overall, the incubation period of the wild type goats is very similar to sheep with the same PRNP genotype [54, 61-63].

The immunohistochemical data did not show differences between the genotypes or between the laboratories involved. More surprising are the results concerning the tissue distribution of $\operatorname{Pr} \mathrm{P}^{\mathrm{D}}$. This regards both the time course of the disease and the tissues involved. Even weak $\operatorname{PrP}^{\mathrm{D}}$ accumulations in peripheral tissue samples were not seen before $12 \mathrm{mpi}$ and only in a single animal. Furthermore, late preclinical goats, which already have a mild to moderate accumulation of $\mathrm{PrP}^{\mathrm{D}}$ in the CNS, not only showed a minor involvement of peripheral tissue samples, but in most cases even a confinement of the $\operatorname{PrP}^{\mathrm{D}}$ accumulations to the Peyer's patches and enteric nervous system of the gut. Only a few animals revealed a mild $\operatorname{PrP}^{\mathrm{D}}$ positive staining reaction in other lymphoid tissues, i.e. tonsil and mesenteric lymph nodes. A more widespread distribution of $\operatorname{PrP}^{\mathrm{D}}$ in lymphoid tissues was only seen in a few clinical goats, late in the incubation period. This is in clear contrast to classical scrapie in sheep and goats as well as BSE in sheep [25, 44, 62, 64]. This unusual $\mathrm{PrP}^{\mathrm{D}}$ distribution pattern is reflected by examinations addressing the infectivity in peripheral tissue samples. As described by [33] and shown by results presented here none of the samples examined from goats early in the incubation period (6 and $12 \mathrm{mpi}$ ) revealed any signs of infectivity, neither in $\mathrm{Tg} 110, \mathrm{Tg} 338$ nor Tgshp IX. On the other hand similar to the results seen in immunohistochemistry a more widespread distribution of BSE infectivity was seen in different peripheral tissue samples of clinical goats among others the popliteal lymph node of goats with different genotype [33] and in the spleen of a wild type goat (lab 3 , data not shown).

A French study showed that the time course of the scrapie pathogenesis is slightly prolonged in goats as compared to sheep [65]. However, the spread of the scrapie agent during the incubation time was quite similar $[25,44,66]$. This was also observed in BSE affected sheep
[61, 63]. $\operatorname{PrP}^{\mathrm{D}}$ accumulations are widespread with distinct $\operatorname{Pr} \mathrm{P}^{\mathrm{D}}$ depositions in follicles and neurons, involving several tissues of the lymphoreticular system as well as the autonomous nervous system early in the incubation period $[25,44,61,63,66]$. In other words TSE neuroinvasion in sheep and goats normally did not occur until a high proportion of lymphoid tissues was positive [66]. On the other hand BSE in cattle spreads almost solely along the autonomous nervous system, with Peyer's patches of the gut as the only lymphoid tissues regularly involved [36, 67]. Unfortunately, CMGC, as a representative sample for the autonomous nervous system, was not available for all goats. However, weak $\operatorname{PrP}^{\mathrm{D}}$ accumulations were seen in two preclinical goats, distinct accumulation in one late preclinical goat as well as in all available samples of the clinical goats (data not shown). Thus, the pathogenesis seen in our BSE infected goats, with no major involvement of the lymphoreticular system is more reminiscent of the disease in cattle. This is supported by the observation that one clinical I/M142 and two late preclinical (one Q/K222 and one M/M142) goats showed no involvement of the LRS at all, even with severe $\operatorname{PrP}^{\mathrm{D}}$ accumulation in the brain stem. It should be noted that the second clinical I/M142 goat revealed a slight staining reaction in rectal follicles and in tonsil. From this point, it remains a speculation what might be the reason behind this unusual distribution pattern in the LRS of BSE infections and, as described by others [66], some scrapie infected goats. There might be an inability of goat lymphoid tissues to accumulate certain $\mathrm{PrP}^{\mathrm{D}}$ 's. On the other hand it is also conceivable that the low amounts of $\operatorname{Pr} \mathrm{P}^{\mathrm{D}}$ detectable in the LRS are due to better clearance abilities in those goats. The animal numbers here are too low to reach a conclusion on the extent to which this pattern is influenced by the genotype, but a similar pattern has been reported before [66].

The two I/M142 with clinical disease and the Q/K222 in the late preclinical state of infection showed incubation times at $44 \mathrm{mpi}$ and $43 \mathrm{mpi}$, respectively. In the goat BSE challenges clinical signs were not recorded for any of the I/M142 and Q/K222 carriers, but a confirmation by IHC of $\mathrm{PrP}^{\mathrm{D}}$ in the CNS of an M/M142 goat at 48 mpi and by mouse bioassay of low level infectivity in the CNS of a Q/K222 goat at $45 \mathrm{mpi}$ [33] (see arrow in Figure 2) was possible. Therefore, as shown previously for goat scrapie $[24,30,31]$, not only the attack ratios but also the incubation periods of BSE in goats appeared influenced by these genotypes. Low attack rates leading to few infected animals and even fewer clinical cases with long incubation periods provides valuable data in support of a protective effect against BSE infection by the M142 and K222 variants. By necessity, our study was mostly conducted in heterozygous goats and both polymorphisms, M142 and 
K222, showed a dominant phenotype as expected from goat scrapie studies and sheep TSE challenges [30, 31, 68]. Resistance to scrapie in the presence of either allele has been shown in many case-control studies and, due to the relative low genotype frequency of homozygotes, the association with resistance has been significant mostly for heterozygotes $[15,20,32,54]$. The survival of the four M/M142 to $48 \mathrm{mpi}$ without clinical disease suggests that homozygotes are at least as resistant to BSE as heterozygotes, which is also evident for scrapie [25]. Similar data for oral BSE exposure of K/K222 goats are still missing, but an attack ratio of $1 / 5$ and an incubation period of 69 mpi for intracerebral inoculation with scrapie [31] combined with evidence that transgenic mice expressing only caprine K222 PrP were resistant to bovine BSE increases the likelihood that $\mathrm{K} / \mathrm{K} 222$ goats will show significant resistance to BSE too [58]. Of course, this is crucial as breeding programs designed to increase the K222 allele frequency will inevitably lead to an increase in the number of homozygous K/K222 animals in goat populations. As a polymorphism that protects from scrapie and BSE, K222 is the strongest candidate for breeding programs for the eradication of TSEs from goats.

However, the K222 allele is not always available for TSE-resistance breeding, since it occurs in variable and often very low frequencies in the European goat population. It varies even within seemingly similar breeds depending on their geographical locations $[17,18,27$, 29]. Introduction of this variant into goat populations with an endemic scrapie problem may be worth considering. The use of alternative PrP polymorphisms associated with a protective effect at least for classical scrapie such as N146D and N146S may be possible for a restricted range of breeds $[69,70]$.

Our challenge data further strengthen the view that the caprine K222 allele is an attractive PRNP variant for TSE resistance breeding since it is not only strongly limiting the transmission of classical scrapie, but as is exemplified here it also has a protective effect against BSE infection.
Competing interests

The authors declare that they have no competing interests.

Authors' contributions

$\mathrm{AB}, \mathrm{OA}$ and $\mathrm{MHG}$ oversaw the challenge experiments in the different laboratories; CF and KT performed the challenge experiments, tissue analyses and mouse bioassays at FLI; PB, IL, CR and FL performed the challenge experiments, tissue analyses and mouse bioassays at INRA-Nouzilly; WG and NH performed the challenge experiments and tissue analyses at Roslin; JGJ performed triplex-WB experiments. CF also collected all the data into a general data base. All authors were involved in the writing of the manuscript lead by JPML. All authors read and approved the final manuscript.

\section{Acknowledgements}

European project FOOD-CT-2006-36353 (GoatBSE), Dutch Ministry of Economic Affairs project WOT-01-002-001.01, the Biotechnology and Biological Sciences Research Council (strategic programme Grant BB/J004332/1 to The Roslin Institute) to WG and $\mathrm{NH}$ and Frederic Bouvier and his group from the INRA Experimental Unit of Bourges "La Sapinière" in France are thanked for the production and supply of experimental goats. We thank Dr. Francis Barillet (INRA, INRA, UR 631, Station d'amélioration géné tique des animaux, BP 52627, 31326 Castanet-Tolosan Cedex, France) for prodividing genotyped goats to CF and FL. We are grateful to the Experimental Infectiology Platform (PFIE, UE-1277, INRA Centre Val de Loire, Nouzilly, France) and the team working in the confinement unit. We are indebted to C. Rossignol and H. Le Roux for their excellent technical assistance in the management and treatment of samples. Dr. Lorenzo Gonzalez is recognized for his outstanding pathology work and comments to the manuscript. We are thankful to Dr. Susanne Niedermeyer for her excellent scientific and practical contribution in the animal experiments at FLI, Greifswald-Insel Riems, Germany. All animal keepers are acknowledged for the excellent care and handling of the experimental goats. Additionally Gesine Kreplin, James Foster, Paula Stewart, Kelly Ryan, and David Parnham are acknowledged for their outstanding technical assistance.

\section{Author details}

${ }^{1}$ Friedrich-Loeffler-Institut, Institute of Novel and Emerging Infectious Diseases, Greifswald-Insel Riems, Germany. ${ }^{2}$ The Roslin Institute and Royal (Dick) School of Veterinary Studies, University of Edinburgh, Easter Bush, Midlothian, UK. ${ }^{3}$ UMR 1282 ISP, Institut National de la Recherche Agronomique (INRA), University of Tours, 37380 Nouzilly, France. ${ }^{4}$ INRA, UMR 1225, Interactions Hôtes Agents Pathogènes, Ecole Nationale Vétérinaire de Toulouse, Toulouse Cedex, France. ${ }^{5}$ Wageningen BioVeterinary Research, Wageningen University \& Research, Houtribweg 39, 8221RA Lelystad, The Netherlands.

\section{Publisher's Note}

Springer Nature remains neutral with regard to jurisdictional claims in published maps and institutional affiliations.

Received: 17 March 2017 Accepted: 19 July 2017

Published online: 19 September 2017

References

1. Griffith JS (1967) Self-replication and scrapie. Nature 215:1043-1044

2. Prusiner SB (1982) Novel proteinaceous infectious particles cause scrapie. Science 216:136-144

3. Bakkebø MK, Mouillet-Richard S, Espenes A, Goldmann W, Tatzelt J, Tranulis MA (2015) The cellular prion protein: a player in immunological quiescence. Front Immunol 6:450

bioassays and sampling applied in the different labs involved.

Additional file 2. Additional file tables A and B: overview of goats challenged with cattle BSE (first passage) and goatBSE (second passage).

Additional file 3. Summary of the immunohistochemical results obtained from the brain stem and different peripheral tissue samples from goats infected with Cattle BSE (first passage).

Additional file 4. Summary of the immunohistochemical results obtained from the brain stem and different peripheral tissue samples from goats infected with goat BSE (second passage).
4. Küffer A, Lakkaraju AK, Mogha A, Petersen SC, Airich K, Doucerain C, Marpakwar R, Bakirci P, Senatore A, Monnard A, Schiavi C, Nuvolone M, Grosshans B, Hornemann S, Bassilana F, Monk KR, Aguzzi A (2016) The prion protein is an agonistic ligand of the $G$ protein-coupled receptor Adgrg6. Nature 536:464-468

5. Schaller O, Fatzer R, Stack M, Clark J, Cooley W, Biffiger K, Egli S, Doherr M, Vandevelde M, Heim D, Oesch B, Moser M (1999) Validation of a western immunoblotting procedure for bovine $\operatorname{Pr} P(\mathrm{Sc})$ detection and its use as a rapid surveillance method for the diagnosis of bovine spongiform encephalopathy (BSE). Acta Neuropathol 98:437-443 
6. Serban D, Taraboulos A, DeArmond SJ, Prusiner SB (1990) Rapid detection of Creutzfeldt-Jakob disease and scrapie prion proteins. Neurology 40:110-117

7. van Keulen LJ, Schreuder BE, Meloen RH, Poelen-van den Berg M, MooijHarkes G, Vromans ME, Langeveld JP (1995) Immunohistochemical detection and localization of prion protein in brain tissue of sheep with natural scrapie. Vet Pathol 32:299-308

8. Wells GA, Scott AC, Johnson CT, Gunning RF, Hancock RD, Jeffrey M, Dawson M, Bradley R (1987) A novel progressive spongiform encephalopathy in cattle. Vet Rec 121:419-420

9. Will RG, Ironside JW, Zeidler M, Cousens SN, Estibeiro K, Alperovitch A, Poser S, Pocchiari M, Hofman A, Smith PG (1996) A new variant of Creutzfeldt-Jakob disease in the UK. Lancet 347:921-925

10. Eloit M, Adjou K, Coulpier M, Fontaine JJ, Hamel R, Lilin T, Messiaen S, Andreoletti O, Baron T, Bencsik A, Biacabe AG, Beringue V, Laude H, Le Dur A, Vilotte JL, Comoy E, Deslys JP, Grassi J, Simon S, Lantier F, Sarradin P (2005) BSE agent signatures in a goat. Vet Rec 156:523-524

11. Jeffrey M, Martin S, González L, Foster J, Langeveld JP, van Zijderveld FG, Grassi J, Hunter N (2006) Immunohistochemical features of PrP(d) accumulation in natural and experimental goat transmissible spongiform encephalopathies. J Comp Pathol 134:171-181

12. Spiropoulos J, Lockey R, Sallis RE, Terry LA, Thorne L, Holder TM, Beck KE, Simmons MM (2011) Isolation of prion with BSE properties from farmed goat. Emerg Infect Dis 17:2253-2261

13. EFSA (2014) Scientific Opinion on the scrapie situation in the EU after 10 years of monitoring and control in sheep and goats. EFSA J 12:378

14. Bossers A, de Vries R, Smits MA (2000) Susceptibility of sheep for scrapie as assessed by in vitro conversion of nine naturally occurring variants of PrP. JVirol 74:1407-1414

15. Belt PB, Muileman IH, Schreuder BE, Bos-de Ruijter J, Gielkens AL, Smits MA (1995) Identification of five allelic variants of the sheep PrP gene and their association with natural scrapie. J Gen Virol 76:509-517

16. Hunter N, Bossers A (2006) The PrP genotype as a marker for scrapie susceptibility in sheep. In: Hörnlimann B, Riesner D, Kretzschmar H (eds) Prions in humans and animals. de Gruyter, Berlin, pp 640-647

17. EFSA (2017) Genetic resistance to transmissible spongiform encephalopathies (TSE) in goats. EFSA J 15(8):4962. doi:10.2903/j.efsa.2017.4962

18. Vaccari G, Panagiotidis CH, Acin C, Peletto S, Barillet F, Acutis P, Bossers A Langeveld J, van Keulen L, Sklaviadis T, Badiola JJ, Andreeoletti O, Groschup MH, Agrimi U, Foster J, Goldmann W (2009) State-of-the-art review of goat TSE in the European Union, with special emphasis on PRNP genetics and epidemiology. Vet Res 40:48

19. Acutis PL, Bossers A, Priem J, Riina MV, Peletto S, Mazza M, Casalone C, Forloni G, Ru G, Caramelli M (2006) Identification of prion protein gene polymorphisms in goats from Italian scrapie outbreaks. J Gen Virol 87:1029-1033

20. Barillet F, Mariat D, Amigues Y, Faugeras R, Caillat H, Moazami-Goudarzi K, Rupp R, Babilliot JM, Lacroux C, Lugan S, Schelcher F, Chartier C, Corbiere F, Andreoletti O, Perrin-Chauvineau C (2009) Identification of seven haplotypes of the caprine PrP gene at codons 127, 142, 154, 211, 222 and 240 in French Alpine and Saanen breeds and their association with classical scrapie. J Gen Virol 90:769-776

21. Billinis C, Panagiotidis CH, Psychas V, Argyroudis S, Nicolaou A, Leontides S, Papadopoulos O, Sklaviadis T (2002) Prion protein gene polymorphisms in natural goat scrapie. J Gen Virol 83:713-721

22. Bouzalas IG, Dovas Cl, Banos G, Papanastasopoulou M, Kritas S, Oevermann A, Papakostaki D, Evangelia C, Papadopoulos O, Seuberlich T, Koptopoulos G (2010) Caprine PRNP polymorphisms at codons 171, 211, 222 and 240 in a Greek herd and their association with classical scrapie. J Gen Virol 91:1629-1634

23. Corbiere F, Perrin-Chauvineau C, Lacroux C, Costes P, Thomas M, Bremaud I, Martin S, Lugan S, Chartier C, Schelcher F, Barillet F, Andreoletti O (2013) PrP-associated resistance to scrapie in five highly infected goat herds. J Gen Virol 94:241-245

24. Goldmann W, Ryan K, Stewart P, Parnham D, Xicohtencatl R, Fernandez N, Saunders G, Windl O, González L, Bossers A, Foster J (2011) Caprine prion gene polymorphisms are associated with decreased incidence of classical scrapie in goat herds in the United Kingdom. Vet Res 42:110

25. González L, Martin S, Siso S, Konold T, Ortiz-Pelaez A, Phelan L, Goldmann W, Stewart P, Saunders G, Windl O, Jeffrey M, Hawkins SA, Dawson M, Hope J (2009) High prevalence of scrapie in a dairy goat herd: tissue distribution of disease-associated PrP and effect of PRNP genotype and age. Vet Res 40:65

26. Goldmann W, Martin T, Foster J, Hughes S, Smith G, Hughes K, Dawson M, Hunter N (1996) Novel polymorphisms in the caprine PrP gene: a codon 142 mutation associated with scrapie incubation period. J Gen Virol 77:2885-2891

27. Vitale M, Migliore S, La Giglia M, Alberti P, Presti VDML (2016) Scrapie incidence and PRNP polymorphisms: rare small ruminant breeds of Sicily with TSE protecting genetic reservoirs. BMC Vet Res 12:141

28. White S, Herrmann-Hoesing L, O'Rourke K, Waldron D, Rowe J, Alverson $J$ (2008) Prion gene (PRNP) haplotype variation in United States goat breeds (Open Access publication). Gen Sel Evol 40:553-561

29. Windig JJ, Hoving RA, Priem J, Bossers A, van Keulen LJ, Langeveld JP (2016) Variation in the prion protein sequence in Dutch goat breeds. $J$ Anim Breed Genet 133:366-374

30. Acutis PL, Martucci F, D'Angelo A, Peletto S, Colussi S, Maurella C, Porcario C, Iulini B, Mazza M, Dell'atti L, Zuccon F, Corona C, Martinelli N, Casalone C, Caramelli M, Lombardi G (2012) Resistance to classical scrapie in experimentally challenged goats carrying mutation K222 of the prion protein gene. Vet Res 43:8

31. Lacroux C, Perrin-Chauvineau C, Corbiere F, Aron N, Aguilar-Calvo P, Torres JM, Costes P, Bremaud I, Lugan S, Schelcher F, Barillet F, Andreoletti O (2014) Genetic resistance to scrapie infection in experimentally challenged goats. J Virol 88:2406-2413

32. White SN, Reynolds JO, Waldron DF, Schneider DA, O'Rourke KI (2012) Extended scrapie incubation time in goats singly heterozygous for PRNP S146 or K222. Gene 501:49-51

33. Aguilar-Calvo P, Fast C, Tauscher K, Espinosa JC, Groschup MH, Nadeem M, Goldmann W, Langeveld J, Bossers A, Andreoletti O, Torres JM (2015) Effect of Q211 and K222 PRNP polymorphic variants in the susceptibility of goats to oral infection with goat bovine spongiform encephalopathy. J Infect Dis 212:664-672

34. Foster JD, Hope J, Fraser H (1993) Transmission of bovine spongiform encephalopathy to sheep and goats. Vet Rec 133:339-341

35. Feraudet C, Morel N, Simon S, Volland H, Frobert Y, Creminon C, Vilette D, Lehmann S, Grassi J (2005) Screening of 145 anti-PrP monoclonal antibodies for their capacity to inhibit PrPSC replication in infected cells. J Biol Chem 280:11247-11258

36. Hoffmann C, Eiden M, Kaatz M, Keller M, Ziegler U, Rogers R, Hills B, Balkema-Buschmann A, van Keulen L, Jacobs JG, Groschup MH (2011) BSE infectivity in jejunum, ileum and ileocaecal junction of incubating cattle. Vet Res 42:21

37. Rigter A, Langeveld JP, Timmers-Parohi D, Jacobs JG, Moonen PL, Bossers A (2007) Mapping of possible prion protein self-interaction domains using peptide arrays. BMC Biochem 8:6

38. González L, Jeffrey M, Siso S, Martin S, Bellworthy SJ, Stack MJ, Chaplin MJ, Davis L, Dagleish MP, Reid HW (2005) Diagnosis of preclinical scrapie in samples of rectal mucosa. Vet Rec 156:846-847

39. Spraker TR, O'Rourke KI, Balachandran A, Zink RR, Cummings BA, Miller MW, Powers BE (2002) Validation of monoclonal antibody F99/97.6.1 for immunohistochemical staining of brain and tonsil in mule deer (Odocoileus hemionus) with chronic wasting disease. J Vet Diagn Investig 14:3-7

40. Harmeyer S, Pfaff E, Groschup MH (1998) Synthetic peptide vaccines yield monoclonal antibodies to cellular and pathological prion proteins of ruminants. J Gen Virol 79:937-945

41. Korth C, Stierli B, Streit P, Moser M, Schaller O, Fischer R, Schulz-Schaeffer W, Kretzschmar H, Raeber A, Braun U, Ehrensperger F, Hornemann S, Glockshuber R, Riek R, Billeter M, Wuthrich K, Oesch B (1997) Prion (PrPSC)specific epitope defined by a monoclonal antibody. Nature 390:74-77

42. Slootstra JW, Puijk WC, Ligtvoet GJ, Langeveld JP, Meloen RH (1996) Structural aspects of antibody-antigen interaction revealed through small random peptide libraries. Mol Divers 1:87-96

43. Andreoletti O, Berthon P, Marc D, Sarradin P, Grosclaude J, van Keulen L, Schelcher F, Elsen JM, Lantier F (2000) Early accumulation of PrP(SC) in gut-associated lymphoid and nervous tissues of susceptible sheep from a Romanov flock with natural scrapie. J Gen Virol 81:3115-3126

44. Niedermeyer S, Eiden M, Toumazos P, Papasavva-Stylianou P, loannou I, Sklaviadis T, Panagiotidis C, Langeveld JP, Bossers A, Kuczius T, Kaatz M, Groschup MH, Fast C (2016) Genetic, histochemical and biochemical studies on goat TSE cases from Cyprus. Vet Res 47:99

45. Le Dur A, Beringue V, Andreoletti O, Reine F, Lai TL, Baron T, Bratberg B, Vilotte JL, Sarradin P, Benestad SL, Laude H (2005) A newly identified type 
of scrapie agent can naturally infect sheep with resistant PrP genotypes. Proc Natl Acad U S A 102:16031-16036

46. Martin S, González L, Chong A, Houston FE, Hunter N, Jeffrey M (2005) Immunohistochemical characteristics of disease-associated PrP are not altered by host genotype or route of inoculation following infection of sheep with bovine spongiform encephalopathy. J Gen Virol 86:839-848

47. Martin S, Jeffrey M, González L, Siso S, Reid HW, Steele P, Dagleish MP, Stack MJ, Chaplin MJ, Balachandran A (2009) Immunohistochemical and biochemical characteristics of BSE and CWD in experimentally infected European red deer (Cervus elaphus elaphus). BMC Vet Res 5:26

48. Jacobs JG, Sauer M, van Keulen LJ, Tang Y, Bossers A, Langeveld JP (2011) Differentiation of ruminant transmissible spongiform encephalopathy isolate types, including bovine spongiform encephalopathy and CH1641 scrapie. J Gen Virol 92:222-232

49. Langeveld JP, Jacobs JG, Erkens JH, Baron T, Andreoletti O, Yokoyama T, van Keulen LJ, van Zijderveld FG, Davidse A, Hope J, Tang Y, Bossers A (2014) Sheep prions with molecular properties intermediate between classical scrapie, BSE and CH1641-scrapie. Prion 8:296-305

50. Castilla J, Gutierrez Adan A, Brun A, Pintado B, Ramirez MA, Parra B, Doyle D, Rogers M, Salguero FJ, Sanchez C, Sanchez-Vizcaino JM, Torres JM (2003) Early detection of PrPres in BSE-infected bovine PrP transgenic mice. Arch Virol 148:677-691

51. Kupfer L, Eiden M, Buschmann A, Groschup MH (2007) Amino acid sequence and prion strain specific effects on the in vitro and in vivo convertibility of ovine/murine and bovine/murine prion protein chimeras. Biochim Biophys Acta 1772:704-713

52. Jeffrey M, Martin S, González L, Ryder SJ, Bellworthy SJ, Jackman R (2001) Differential diagnosis of infections with the bovine spongiform encephalopathy (BSE) and scrapie agents in sheep. J Comp Pathol 125:271-284

53. Lloyd S, Mead S, Collinge J (2011) Genetics of prion disease. Top Curr Chem 305:1-22

54. Hunter N, Houston F, Foster J, Goldmann W, Drummond D, Parnham D, Kennedy I, Green A, Stewart P, Chong A (2012) Susceptibility of young sheep to oral infection with bovine spongiform encephalopathy decreases significantly after weaning. J Virol 86:11856-11862

55. Ryder SJ, Dexter GE, Heasman L, Warner R, Moore SJ (2009) Accumulation and dissemination of prion protein in experimental sheep scrapie in the natural host. BMC Vet Res 5:9

56. St Rose SG, Hunter N, Matthews L, Foster JD, Chase-Topping ME, Kruuk LE, Shaw DJ, Rhind SM, Will RG, Woolhouse ME (2006) Comparative evidence for a link between Peyer's patch development and susceptibility to transmissible spongiform encephalopathies. BMC Infect Dis 6:5

57. Carp RI, Callahan SM (1991) Variation in the characteristics of 10 mousepassaged scrapie lines derived from five scrapie-positive sheep. J Gen Virol 72:293-298
58. Aguilar-Calvo P, Espinosa JC, Pintado B, Gutierrez-Adan A, Alamillo E, Miranda A, Prieto I, Bossers A, Andreoletti O, Torres JM (2014) Role of the goat K222-PrP(C) polymorphic variant in prion infection resistance. J Virol 88:2670-2676

59. Espinosa JC, Andreoletti O, Castilla J, Herva ME, Morales M, Alamillo E, San-Segundo FD, Lacroux C, Lugan S, Salguero FJ, Langeveld J, Torres JM (2007) Sheep-passaged bovine spongiform encephalopathy agent exhibits altered pathobiological properties in bovine-PrP transgenic mice. J Virol 81:835-843

60. EFSA (2015) Scientific Opinion on a request for a review of a scientific publication concerning the zoonotic potential of ovine scrapie prions. EFSA J 13:4197

61. Bellworthy SJ, Dexter G, Stack M, Chaplin M, Hawkins SA, Simmons MM Jeffrey M, Martin S, González L, Hill P (2005) Natural transmission of BSE between sheep within an experimental flock. Vet Rec 157:206

62. Saunders SE, Bartz JC, Bartelt-Hunt SL (2009) Prion protein adsorption to soil in a competitive matrix is slow and reduced. Environ Sci Technol 43:7728-7733

63. van Keulen LJ, Vromans ME, Dolstra CH, Bossers A, van Zijderveld FG (2008) Pathogenesis of bovine spongiform encephalopathy in sheep. Arch Virol 153:445-453

64. van Keulen LJ, Schreuder BE, Vromans MEW, Langeveld JP, Smits M (2000) Pathoegenesis of natural scrapie in sheep. Arch Virol 16:57-71

65. EFSA (2010) Scientific Opinion on BSE/TSE infectivity in small ruminant tissues. EFSA J 8:1875

66. González L, Martin S, Hawkins SA, Goldmann W, Jeffrey M, Siso S (2010) Pathogenesis of natural goat scrapie: modulation by host PRNP genotype and effect of co-existent conditions. Vet Res 41:48

67. Kaatz M, Fast C, Ziegler U, Balkema-Buschmann A, Hammerschmidt B, Keller M, Oelschlegel A, McIntyre L, Groschup MH (2012) Spread of classic BSE prions from the gut via the peripheral nervous system to the brain. Am J Pathol 181:515-524

68. Houston F, Goldmann W, Foster J, González L, Jeffrey M, Hunter N (2015) Comparative susceptibility of sheep of different origins, breeds and PRNP genotypes to challenge with bovine spongiform encephalopathy and scrapie. PLoS One 10:e0143251

69. Papasavva-Stylianou P, Kleanthous M, Toumazos P, Mavrikiou P, Loucaides P (2007) Novel polymorphisms at codons 146 and 151 in the prion protein gene of Cyprus goats, and their association with natural scrapie. Vet J 173:459-462

70. Papasavva-Stylianou P, Windl O, Saunders G, Mavrikiou P, Toumazos P, Kakoyiannis C (2011) PrP gene polymorphisms in Cyprus goats and their association with resistance or susceptibility to natural scrapie. Vet J 187:245-250

\section{Submit your next manuscript to BioMed Central and we will help you at every step:}

- We accept pre-submission inquiries

- Our selector tool helps you to find the most relevant journal

- We provide round the clock customer support

- Convenient online submission

- Thorough peer review

- Inclusion in PubMed and all major indexing services

- Maximum visibility for your research

Submit your manuscript at www.biomedcentral.com/submit
() BioMed Central 